\title{
Dijital Diplomaside Instagram Aracılığıyla Sosyal Medya Fenomenlerinin Kullanımı: Troya Ören Yeri Örneği
}

\author{
İlgar Seyidov \\ Dr. Öğr. Üyes \\ ilgar.seyidov@atilim.edu.tr \\ Atılım Üniversitesi Işletme Fakültesi \\ Halkla Iliş̧kiler ve Reklamcılık Bölümü \\ ORCID: 0000-0001-8420-1413 \\ Beris Artan Özoran \\ Dr. Öğr. Üyesi \\ bartan@ankara.edu.tr \\ Ankara Üniversitesi İletişim Fakültesi \\ Halkla İlişkiler ve Tanıtım Bölümü \\ ORCID: 0000-0002-1814-4323
}

\begin{abstract}
Use of Influencers via Instagram in Digital Diplomacy: Case Study Analysis of Troya Ruins

After the Cold War, while the concept of "hard power" lost its influence, a new concept called "soft power" in the field emerged, and this new concept has been discussed in various studies since 1990. The soft power concept represents a diplomacy process that is carried out without applying oppressive and coercive power and restrictions. Another concept that emerged within the framework of soft power was public diplomacy. Public diplomacy aims to create a positive image and to gain trust by influencing the public with different fields such as culture, tourism, music, language, food, education. Technological developments, the internet and developing network systems, new media tools have reshaped public diplomacy practices and created the concept of "digital diplomacy". Digital diplomacy focuses on the use of different digital platforms and social networking sites for more effective and interactive public diplomacy
\end{abstract}


activities. One of these effective tools is the photo/video sharing platform Instagram. Within the scope of this study, the understanding of digital diplomacy is discussed through Instagram. As a research object, the Instagram accounts of five social media influencers who were invited to Çanakkale by the Ministry of Tourism and Culture, due to the 20th anniversary of Troy Ruins being included in the World Cultural Heritage list in 2018, were chosen. As the research, a descriptive case study was conducted. The findings showed that while the interactive potential of Instagram was not used sufficiently, the use of emotion and visual cultural elements in terms of digital diplomacy was used effectively.

keywords: Digital diplomacy, Instagram, Troya Ruins, social media influencers, case study

\section{Résumé}

\section{Utilisation d'influenceurs via Instagram dans la diplomatie numérique : étude de cas sur les ruines de Troya}

Après la guerre froide, le concept de "puissance dure " a perdu de son influence, un nouveau concept dans le domaine de la diplomatie, le "puissance douce ", a émergé et fait l'objet de diverses études depuis 1990 Le concept de décrit essentiellement un processus de diplomatie mené sans appliquer de pouvoir et de restrictions oppressifs et coercitifs. Un autre concept qui a émergé dans le cadre du concept de puissance douce est la diplomatie publique. La diplomatie publique vise à créer une image positive et à gagner la confiance en influençant l'autre public dans différents domaines tels que la culture, le tourisme, la musique, la langue, la nourriture et l'éducation. Les développements technologiques, I'Internet et le développement du système de réseau, les nouveaux outils médiatiques ont remodelé les pratiques de la diplomatie publique et créé le concept de "diplomatie numérique ". La diplomatie numérique se concentre sur I'utilisation de différentes plateformes numériques et sites de réseaux sociaux pour mener des activités de diplomatie publique plus efficaces et interactives. L'un de ces outils efficaces est le site de partage de photos / vidéos Instagram. Dans le cadre de cette étude, la compréhension de la diplomatie numérique est discutée sur Instagram. Ce sont les comptes Instagram de 5 phénomènes de médias sociaux invités à Çanakkale par Le Ministère du Tourisme et de la Culture en raison du 20e anniversaire de l'inscription des ruines de Troya sur la liste du patrimoine culturel mondial en 2018 font l'objet de recherche. L'étude de cas descriptive a été choisie comme technique de recherche. Les résultats ont montré que le potentiel interactif d'Instagram n'était pas suffisamment utilisé, mais que les éléments culturels émotionnels et visuels en termes de diplomatie numérique étaient utilisée efficacement.

mots-clés: Diplomatie numérique, Instagram, ruines de Troya, phénomènes des médias sociaux, étude de cas 


\section{Öz}

Soğuk Savaş sonrası "sert güç" kavramının etkisini kaybetmesiyle, diplomasi alanında yeni bir kavram olan "yumuşak güç" ortaya çıkmış ve 1990 yılında itibaren çeşitli araştırmalarla tartışılmıştır. Yumuşak güç anlayışı temelde baskıcı ve zorlayıcı güç, kısıtlama uygulamadan yürütülen bir diplomasi sürecini betimlemektedir. Yumuşak güç anlayışı çerçevesinde ortaya çıkan diğer bir kavram ise kamu diplomasisi olmuştur. Kamu diplomasisi, karşı kamuyu kültür, turizm, müzik, dil, yemek, eğitim gibi farklı alanlarla etkileyerek olumlu bir imaj oluşturma ve güven kazanma amacını içermektedir. Teknolojik gelişmeler, internet ve gelişen ağ sistemi, yeni medya araçları kamu diplomasisi uygulamalarını da yeniden şekillendirerek, "dijital diplomasi" kavramını ortaya çıkarmıştır. Dijital diplomasi, kamu diplomasisi faaliyetlerinin daha etkili, interaktif ve etkileşimli yürütülmesi için farklı dijital platformlar ve sosyal ağ sitelerinin kullanımına odaklanmaktadır. Bu etkili araçlardan biri de fotoğraf/video paylaşım sitesi Instagram'dır. Bu çalışma kapsamında dijital diplomasi anlayışı Instagram üzerinden ele alınmaktadır. Instagram'ın dijital diplomasi aracı olarak kullanılması "Troya Ören Yeri" örnek olayı çerçevesinde betimsel örnek olay tekniği ile incelenmiştir.2018 yılında Troya yılı kapsamında Troya Ören Yeri'nin UNESCO Dünya Kültür Mirası Listesi'ne alınmasının 20'ci yılı nedeniyle Turizm ve Kültür Bakanlığı tarafından Instagram üzerinden beş sosyal medya fenomeni bölgeye davet edilmiş ve sosyal medya fenomenleri Türkiye'nin tanıtımı için Instagram üzerinden paylaşımlar gerçekleştirmiştir. Bulgular, Instagram'ın etkileşimli potansiyeline karşın genel olarak yeterince yönetilemediğini ortaya koyarken, sosyal medya fenomenlerinin ağırıkı olarak tarihi ve turistik bilgiler paylaştığını göstermiştir.

anahtar kelimeler: Dijital diplomasi, Instagram, Troya Ören Yeri, sosyal medya fenomenleri, örnek olay incelemesi 


\section{Giriş}

Soğuk Savaş ve sonrasında uluslararası ilişkiler alanında yeni bir diplomasi anlayışı olarak- "yumuşak güç" kavramı tartışımaya başlanmıştır. Uzun yıllardır kullanılan, askeri müdahale ve baskıcı stratejiler gibi özellikleri barındıran "sert güç" artık gelişmekte olan iletişim sistemi ve teknolojileri ile birlikte önemini kaybetmeye başlayarak yerini iletişimsel pratikleri içeren bir anlayışa bırakmıştır. Kamu diplomasisinin önemli bir parçası haline gelen yumuşak güç, 2000 'li yıllarla ortaya çıkan dijital medya teknolojileri ile birlikte etkileşimsel boyut kazanarak tarih ve kültür, eğitim, turizm, müzik gibi alanları kullanarak yeni bir boyut kazanmıştır.

Diplomasi, uluslararası ilişkilerin "makine dairesi" olarak tanımlanabilir (Adesina, 2017, s.2). Kavram etimolojik olarak Eski Yunanca bir terim olan ve "ikiye katlamak" anlamına gelen "diploma" sözcüğünden gelmektedir. Bu şekilde anlamlandırımasının nedeni ise diplomanın Eski Yunan'da ve Roma Imparatorluğu'nda resmi ve yabancı topluluklarla ilişkilere yönelik bilgileri içeren belgelerin katlanmış biçimde korunması ve arşivlenmesi ile ilgilidir. 1976 yılında Edmund Burke tarafından uluslararası ilişkiler alanı çerçevesinde tanımlanana kadar, dipIomasi arşiv alanı içinde değerlendirilmiştir. Edmund Burke diplomasiyi uluslararası ilişkilerin yürütülmesi ya da yönetilmesi şeklinde tanımlamışırı. (Köse, 2017, s.2349). Soğuk Savaş sonrasında diplomasi kavramı, farklı şekillerde ancak benzer içeriklerle tanımlanmıştır. Örneğin, Bull'a (1997) göre diplomasi, uluslararası düzeyde devlet kurumlarının resmi temsilcilerinin barışçıl yollara başvurarak yürüttüğü davranışlar bütünüdür. Watson (1984) ise diplomasiyi resmi olarak bağımsızığı tanınan siyasi varlıklar arasındaki müzakere süreci olarak tanımlamıştır. 2000'li yıllarla birlikte "yumuşak güç" anlayışına dayalı "kamu diplomasisi" kavramı popüler hale gelmiş ve uluslararası arenada yaygın şekilde kullanılmaya başlanmıştır. Kamu diplomasisi, ulusların diğer ülkelerin kamularında olumlu imaj/ algı oluşturma ve desteğini kazanma amacıyla yürüttüğü çabaları kapsamaktadır. Bu anlamda "yumuşak gücün" etki alanını artıran en önemli araç ise internet ve dijital uygulamalardır (Harris, 2013, s.18).

Yumuşak güç kavramı, ilk kez 1990 yııında Joseph S. Nye tarafından kullanılmıştır. Nye'a (2004, s.256) göre yumuşak güç, baskı ve zorlayıcı güç kullanılmadan istenilen hedefe ya da amaca ulaşmayı ifade etmektedir. Zıt anlamlısı olan "sert güç" ise ekonomik veya askeri gücün diplomatik amaçlar için kullanılması anlamına gelmektedir. Özellikle "güç" sorunsalına odaklanan Nye (2009, s.160), kavramı başkalarının davranışlarını değiştirmeye yönelik bir etki süreci olarak yorumlamaktadır. Bu anlamda üç temel yoldan bahsetmektedir: baskı, finansal güç ve ilgi çekme (cazibe). Sert güce dayalı diplomasi, baskı ve finansal gücü -ekonomik olarak karşı tarafı kendinde bağımlı hale getirme- aktif olarak kullanırken, yumuşak güç odaklı kamu diplomasisi, çeşitli etkileşimsel araçlarla karşı tarafın ilgisini çekerek etkilemeye çalışmaktadır. 
Yumuşak güçte temel amaç, alıcı ülkedeki kamulara olumlu mesajlar ileterek etki yaratmaktır. Bu nedenle yumuşak gücün başarılı olması için gönderilen mesajın kaynağı, içeriği ve alıcı tarafın algısı önemli etkenlerdir (Çavuş, 2012, s.26). Diğer taraftan yumuşak güce sahip olmak yumuşak gücü tam anlamıyla kullanabilmek anlamına gelmemektedir. İster sert ister yumuşak güç olsun temelde üç koşulun sağlanması gerekmektedir: (i) devletlerin diğer aktörleri etkileyebilmesi için yeteri kadar imkân ve varlığa sahip olması; (ii) aktörlerin bu güce sahip olma bilinçleri ve (iii) diğer aktörlerin bu gücün farkına varması. Diğer bir ifadeyle, güç oluşturma davranışsal olarak tanımlansa da etkileşimsel olarak uygulanmaktadır (Yapıcı, 2015, s.9). Bir devletin tarihi ve kültürü yumuşak güç için kullanılabilecek en önemli kaynaklardır. Örneğin, ABD ve Çin yumuşak güç anlamında ticari gücü etkili şekilde kullanmaktadır. Japonya, kültürel göstergeler üzerine odaklanarak kendine özgü müzik ve çizgi filmlerini, video oyunları ve gastronomiyi öne çıkarmaktadır (Heng, 2010, ss.277-288). Almanya başarılı bir spor diplomasisi tercih ederken, Katar ise turizm, markalaşma ve ticaret gibi farklı yumuşak güç unsurlarına odaklanmıştır (Grix ve Brannagan, 2016, ss.263-267). Rusya, "olumlu bir ülke imajı" oluşturmak amacıyla "yüksek kültür" anlayışını benimseyerek çeşitli sanat etkinliklerini hem eski Sovyet bölgesinde hem de uluslararası arenada etkin şekilde kullanmıştır (Sergunin ve Karabeshkin, 2015, ss.353-355). Türkiye de yumuşak gücün önemini anlayan ve bu konuda stratejiler geliştiren ülkelerden biridir. Türkiye'nin uyguladığı yumuşak güç kaynakları arasında diziler, kültürel ve turistik gezi programları, eğitim, insani yardımlar ve benzeri öğeler önemli yere sahiptir (Çavuş, 2012, s.29; Sancar, 2016, s.17). Bu uygulamaların gerçekleşmesinde ise dijital medya etkin bir rol oynamaktadır. Internet ve dijital teknolojilere bağlı olarak gerçekleştirilen kamu diplomasisi süreçleri ise dijital diplomasi anlayışı çerçevesinde ele alınmaktadır.

Bu çalışmada Instagram'ın dijital diplomasi aracı olarak işlevi tartışıımaktadır. Bu kapsamda çalışmanın örneklemini Kültür ve Turizm Bakanlığı́nın desteğiyle 2018 yılında yedi sosyal medya fenomeninin davetiyle gerçekleştirilen Troya Ören Yeri'nin tanıtımı oluşturmaktadır. Çalışmanın amacı dijital medya platformu olan Instagram'ın aynı zaman bir diplomasi aracı olarak nasıl kullanıldığını seçilen örneklem üzerinden incelemektir. Dijital diplomasi uygulamalarına yönelik farkIı çalışmalar (Korkmaz ve Böyük, 2019; Çömlekçi, 2019; Tuncer, 2020; Özlü ve Alan, 2020) yapılmış olsa da temelde Twitter ve Facebook'un etkisi ve önemi vurgulanmıştır. Türkçe literatür incelendiğinde Instagram ve diplomasi ilişkisine odaklanan yalnızca bir çalışma olduğu görülmüştür. Sancar (2017b) tarafından yapılan çalışmada "Come See Turkey" örneği üzerinden Instagram'ın dijital dipIomasi açısından önemi ve etkisi ele alınmıştır. Bu makale kapsamında ise, diğerlerinden farklı olarak, dijital diplomaside Instagram kullanımı, sosyal medya fenomenlerinin paylaşımları üzerinden ele alınmaktadır. Örnek olay olarak, "Troya Ören Yeri"nin tanıtımı için gerçekleştirilen dijital diplomasi çalışması seçilmiştir. Sosyal medya fenomenlerinin paylaşımları betimsel vaka analizi yöntemiyle incelenmiştir. Araştırma kapsamında sosyal medya fenomenlerinin kaç paylaşım gerçekleştirdiği, paylaşımların içeriği, Türkiye'nin hangi özellikleriyle ilgili bilgiler paylaşıldığı ve paylaşımların etkileşim düzeyi ele alınmıştır. 


\section{Dijital Diplomaside Sosyal Medya Kullanımı}

Geleneksel anlamıyla diplomasi iki uluslararası aktörün etkileşim kurarken ulusal bir çevrede yönetim girişiminde bulunması anlamına gelmektedir. Kamu diplomasisi ise uluslararası bir aktörün yabancı bir kamuoyu ile etkileşime girerek o çevreyi yönetme girişimidir. Kamu diplomasisi çeşitli kültürel alanları içinde barındırmaktadır. Kültürel çatı altında eğitim, dil, müzik, yemek, sanat, bilim ve turizm gibi kültürlerarası diyaloğun gelişmesine etki gücüne sahip faktörler ön plana çıkmaktadır. Özellikle turizm alanı kamu diplomasisinin en güçlü araçlarından biri olarak görülmektedir. Nedeni ise turizmin devletlerin yabancı kamulara ulaşmasında ve farklı kamular arasında en kolay iletişimin sağlanmasında etkin rol oynamasıdır (Sancar, 2017a, s.90). Diğer taraftan internetin yaygınlaşması, teknolojik yenilikler ve ortaya çıkan yeni iletişimsel ve sosyo-kültürel değişimler kamu diplomasisi ile diplomasinin iç-içe girmesine neden olurken, küresel boyutta toplumlar arası etkili halkla ilişkiler stratejilerinin oluşmasına zemin yaratmıştır. Sonuç olarak diplomasinin de daha etkileşimli olmasına katkı sağlamıştır (Özlü ve Alan, 2020, s.1347).

Yeni iletişim teknolojilerinin ortaya çıkması diplomasi anlayışını da dönüştürmüştür. Geleneksel kamu diplomasisi, hükümet ve dışişleri uzmanları tarafından gerçekleştirilmektedir. Resmi ve bilimsel bilgi aktarımına dayanmaktadır. Geleneksel kamu diplomasisinde kamunun pasif olduğu kabul edilmektedir, tek yönlü, asimetrik ve bilgiye dayalı olarak gerçekleşmektedir. Aynı zamanda davranış değişikliği hedefi bulunmamaktadır. Yeni kamu diplomasisi ise gelenekselin tersine, hükümet dışı uygulayıcılar tarafından gerçekleştirilmektedir. Resmi olmayan kanallar kullanılmakta ve kamunun aktif olduğu kabul edilmektedir. Geleneksel anlayışın tersine, iki yönlü, simetrik ve diyaloğa dayalı olarak gerçekleşmektedir. Aynı zamanda yeni kamu diplomasisi anlayışı, davranış değişikliğini hedeflemektedir (Snow, 2009, s.8). Yeni kamu diplomasi anlayışının iki yönlü, simetrik ve diyaloğa dayalı olarak gerçekleşmesi hedefi, yeni iletişim teknolojilerinin diplomasi için önemini artırmış, yeni iletişim teknolojileri üzerinden diplomasi çalışmaları yürüten çalışmalar çoğalmıştır.

Dijital teknolojiler, iş yerlerini dijitalleştirmekte, nesneleri yönetmekte, ulaşılabilir ve yeniden kullanılabilir bir veri haline getirmektedir. Böylece, büyük güçler, küçük ölçekli STK'lar (Sivil Toplum Kuruluşları) ve diplomatlar amaçlarını, çıkarlarını ve düşüncelerini kullanılabilir bir yazılım haline getirebilmektedir. Sosyal, politik ve ekonomik faaliyet aynı zamanda teknolojik bir önem de kazanmaktadır (Melissen, 2017). Çünkü temelde internet bilgi depolama, değiş-tokuşu ve yayılımı gibi önemli olanaklar sağlayarak çeşitli kamusal ve özel iletişim platformlarının oluşmasına zemin yaratmaktadır (Adesino, 2017, s.2).

Teknolojik yenilikler kamu diplomasisinde de yenilikleri ortaya çıkarmıştır. Internet, akıllı telefonlar ve sosyal medya üçlüsü, geniş kitlelere kolay ulaşma ve siyasal olarak hem yerel hem de küresel anlamda etkili olmaya zemin yaratmış- 
tır. Geleneksel diplomasi anlayışındaki tek yönlü iletişim pratikleri artık işlevsiz kalmıştır. Kitleler, kamular artık daha interaktif ve yinelemeli bir iletişime intiyaç duymaktadır (Collins, DeWitt ve LeFebvre, 2019, s.80). Diğer taraftan sert gücün yerine artık yumuşak gücün daha etkili kullanılmasıyla birlikte dijital platformlar önemli iletişim araçları haline gelmiştir. Bu bağlamda "dijital diplomasi" dış politikanın dijital medya üzerinden yürütülmesini içeren bir kavram olarak popülerlik kazanmıştır (Özlü ve Alan, 2020, s.1348).

Dijital diplomasi kavramı ilk kez 2001 yllında iki düşünce üzerine kurulu olarak tanımlanmıştır. IIlki, kamu diplomasisinin yürütülmesinde yeni sistem olarak, ikincisi ise yabancı topluluklarla aktif bir şekilde etkileşim kurulmasına yönelik bir diyalog süreci olarak yorumlanmasıdır (Köse, 2017, s.2354). Hanson'a (2012) göre internet ve bilgi iletişim teknolojilerinin gelişimi dijital diplomasi anlamında sekiz temel prensibi içermektedir:

1- Bilgi Yönetimi: Resmi bilgilerin sürdürülmesi, paylaşımı ve uluslararası arenada ulusal çıkarların korunmasına yönelik kullanımı;

2- Kamu Diplomasisi: Çevrimiçi göç yoluyla yabancı kamularla irtibata geçme ve önemli mesajlarla etkileme;

3- Enformasyon Yönetimi: Yoğun enformasyon akışını kontrol etme ve politika geliştirme için kullanma;

4- Konsolosluk Illetişimi: Doğrudan ve kişisel iletişim kanallarıyla vatandaşların seyahat ve kriz durumlarını çözme;

5- Afete Müdahale: Karmaşık ağ teknolojilerini afete müdahale durumlarında kullanma;

6- İnternet Özgürlüğü: Demokrasi bağlamında interneti açık ve özgür tutmak için teknolojileri kullanma;

7-Dış Kaynaklar: Gerekli dış kaynaklardan ulusal çıkarlar için kullanma;

8- Politika Planlama: Dijital araçların kullanılmasıyla ulusal politikaların ve bürokrasinin kurumsallaşmasında koordinasyon kurma ve yönetme.

Günümüzde dijital diplomasi, kamu diplomasisi için yeni olanaklar ve araçlar sunmaktadır. Özellikle hükümetler, küresel medya ekolojisi içerisinde daha uzun vadeli ilişkiler kurma ve sadece bilgi aktarımından öte, iki yönlü- simetrik iletişim kurmaya çalışmaktadır (Kampf, Manor ve Segev, 2015, s.337). Dijital diplomasi, geniş anlamda Whatsapp uygulamasından e-posta sistemine, video konferansa kadar çeşitli iletişim yöntemlerini içerse de dar anlamda sosyal medya platformlarını kapsamaktadır (Yağmurlu, 2019, s.1272). Bu anlamda simetrik iletişim ve ilişki kurmaya yönelik özellikle sosyal medya araçları etkin olarak kullanılmaktadır. Sosyal medya ülkeler arasında bağlantılar kurmakta ve böylece kamu diplomasisi bu bağlantıları kullanarak çeşitli halkla ilişkiler teknikleri uygulamaktadır (Boyle, 2019, s.122). Sosyal medyanın küresel boyutta siyasal katılım için potansiyeli Arap Baharı ile birlikte dikkat çekmiş ve uluslararası çevrede farklı diplomatik amaçlar için geniş 
şekilde kullanılmaya başlanmıştır. Twitter, Arap Baharı sürecinde genç aktivistlere muhalif söylemi yaymada, anlatıları oluşturmada ve devrimin canlı görüntülerini tüm dünyaya ulaştırmada en önemli ve etkili iletişimsel ortamı sunduğu için "Twiplomasi" yani Twitter diplomasisi kavramını da ortaya çıkarmıştır (Rashica, 2018, s.25).

Sosyal medya dijital diplomasi anlayışı çerçevesinde "arabulucu" bir görev üstlenmektedir. Özellikle kriz durumlarında siyasal kurumların veya kişilerin sadece iç ve dış kamulara değil aynı zamanda diğer medya kuruluşlarına da en kısa zamanda ulaşmasında ve etkileşim oluşturmasında etkili rol oynamaktadır. Diğer bir ifadeyle eş zamanlı bir diplomasi sürecini ortaya çıkarmaktadır. Bu anlamda Twitter etkin şekilde kullanılmaktadır. Özellikle ülkelerin Dış Işleri Bakanlıkları Twitter aracılığıyla kamuların çıkarlarını öğrenebilmekte ve çevrimiçi stratejiler belirleyebilmektedir (Manor ve Crilley, 2020, 2. 71-72). Herhangi önemli bir kriz ya da sorun ile ilgili hızlı şekilde öğrenilen ve iletilen bilgiler, çözümlerin daha sistematik ve hızı şekilde oluşturulabilmesine olanak sağlamaktadır. Örneğin, herhangi bir bölgede ortaya çıkan kriz durumunun kendi ülkesindeki kamuya nasıl yansıyacağını anlamak, süreci izlemek ve hızlı bilgi akışını sağlamak amacıyla elçiliklerde oluşturulan Whatsapp grupları etkili olmaktadır. Bu tür çevrimiçi gruplar, kriz yönetimini kolaylaştırmakta ve gerçek-zamanlı bilgi toplamayı etkinleştirmektedir. Bu da karar alma mekanizmalarına ve kamuyu bilgilendirme sürecine olumlu şekilde katkı sağlamaktadır (Rashica, 2018, s.81).

Twitter metin odaklı bir sosyal medya platformu iken, Instagram görsele odaklanmaktadır. Instagram'ın görsele odaklanması, kamu diplomasisinin karşı kamuyu kültür, turizm, yemek gibi farklı alanlarda etkileme ve ülke için olumlu bir imaj oluşturma hedefi düşünüldüğünde oldukça önemlidir. Instagram üzerinden uygulanan diplomasi çalışmalarında görsel ön plana çıkmaktadır. Böylelikle ülkenin turistik bölgeleri, kültürel zenginliği ya da yemekleri karşı kamuya görsel olarak sunulabilir. Dolayısıyla Instagram, ülkenin görsel olarak sunulması fırsatını sunmaktadır.

Genel anlamda sosyal medyanın hem devlet hem de diğer devlet-dışı aktörlerle (STK'lar, aktivist gruplar, vd.) bağlantı kurma ve örgütlenmeye yönelik olanaklar sunması etkili bir halkla ilişkiler aracı olarak kullanılmasına zemin yaratmıştır (Spry, 2018, s.63). Bu bağlamda dijital diplomasi literatürü sosyal medyanın ülkelerin "olumlu imajının" oluşmasında katılım ve diyalog kurulması açısından önemli bir araç olduğunu vurgulamaktadır. Bunun temel nedeni devlet yetkililerinin dijital ortam araclığıyla iç ve dış kamulara doğrudan ulaşabilmesidir (Ittefaq, 2019, ss.50-53).

Sosyal medya uygulamalarının dijital diplomaside önemli rol oynamasının temel nedenlerinden biri de örgütsel olarak kapsamlı bir iletişim stratejisi için olanaklar sunmasıdır. Dijital dünyanın eş zamanlı iletişim, etkileşim, geliştirilebilir içerik, küresel erişim ve çoklu medya ortamı seçeneği gibi özellikleri hem örgütlere hem de bireylere etkili ilişki kurabilme fırsatı sağlamaktadır. En önemlisi ise geleneksel medyadan çok daha ucuz ve hızlı bir donanıma sahiptir. Mekân-zaman ayrımı olmaksızın hizmet sunabilmektedir (Yağmurlu, 2019, s.1275). Straus ve arkadaşlarına 
(2015) göre dijital diplomaside sosyal medya kullanımı altı etkin iletişim stratejisini ortaya çıkarmaktadır: tarafların dâhil edildiği etkileşimli iletişim, kişiselleştirilmiş iletişim, duygu kullanımı, güncel konulara iliş̧kin bilgi paylaşımı, şeffaf iletişim ortamı ve ağ oluşturma. Paydaşları, kitleleri, tarafları "dâhil etme" önemli bir süreçtir. Çünkü bu dâhil etme süreci verici ülkenin alıcı kamuya doğru şekilde ulaşmasına ve olumlu imaj oluşturmasına katkı sağlamaktadır (Harris, 2013).

\section{Yöntem}

Soğuk Savaş sonrasında "sert güç" ün etkisini kaybetmesi ve "yumuşak güç" ün önem kazanmasıyla birlikte "kamu diplomasisi" devletler için etkili bir araç haline gelmiştir. Uluslararası kamuyu kültür, turizm, müzik gibi alanlarla etkileyerek olumlu bir imaj oluşturma amacını taşıyan kamu diplomasisi için, yeni iletişim teknolojileri önemli fırsatlar sunmaktadır. Yeni iletişim teknolojilerini kullanan dijital diplomasi interaktif ve etkileşimli bir ortamı mümkün kılmaktadır. Bu araştırma, dijital diplomasi aracı olarak Instagram üzerine odaklanmaktadır. Instagram, "We are Social and Hootsuite 2020" (We Are Social Raporu, 2020) raporuna göre Facebook ve Youtube'un ardından bir milyar kullanıcı sayısıyla, en çok kullanılan üçüncü sosyal medya platformudur. Türkiye örneğinde Facebook ve Youtube'un devlet kurumları tarafından dijital diplomasi aracı olarak kullanıldığı bir örnek bulunamadığı için, araştırmada Instagram'a odaklanılmıştır.

Araştırma kapsamında örnek olay olarak "Troya Ören Yeri" için gerçekleştirilen dijital diplomasi çalışması seçilmiştir. Turizm, bir ülkenin kamu diplomasisi mesajlarının iletilmesi açısından önem taşımaktadır. Türkiye bağlamında düşünüldügünde ise, turizm konusunda gerçekleştirilen tanıtım ve iletişim çalışmalarının diğer ülke kamularının Türkiye ile ilgili düşünceleri üzerinde etkili olduğu bilinmektedir. Türkiye Cumhuriyeti Turizm ve Kültür Bakanlığı, 2023 hedefleri doğrultusunda, turizm iletişimi konusunda yenilikler gerçekleştireceğini açıklamıştır. Turizm ve Kültür Bakanı Nuri Ersoy, yeni strateji planları çerçevesinde iletişimin değiştiğini ve bu nedenle sosyal medya ve dijital tanıtımların ön plana çıktığını, yeni çalışmalarında sosyal medya fenomenlerinin de kullanılacağını belirtmiştir. Bu kapsamda Türkiye'nin turizm iletişimi hedefleri için sosyal medya fenomenlerini kullandığı çalışmaların ortaya çıkmaya başladığı görülmektedir.

Bölge turizminin sosyal medya fenomenlerinin tanıtılması için "Troya Ören Yeri" örneğinden önce gerçekleştirilen çalışmalar bulunmaktadır. 2017 yılında Isparta'da bulunan "Lavanta Bahçeleri" nin tanıtımı için bölgeye yerli sosyal medya fenomenleri davet edilmiştir.' Aynı yıl Muğla Büyükşehir Belediyesi, Muğla'nın tanıtımı için dünya çapında 30 milyon takipçisi olan sosyal medya fenomenlerini davet etmiştir. ${ }^{2}$ Bu araştırmada "Troya Ören Yeri" örneğinin seçilmesinin nedeni çalışmanın hem uluslararası alanda etkisi olan sosyal medya fenomenleri davet

1 Lavanta Bahçeleri Tanıımı. Erişim 22 Aralık 2020, https://isparta.ktb.gov.tr/TR-183615/siz-hala-lavanta-kokulu-koyu-gormediniz-mi.html

2 Büyükşehir Muğla Sosyal Medya Fenomenleri ile Buluşuyor. Erişim 23 Aralık 2020, https://www. mugla.bel.tr/haber/buyuksehir-muglayi-sosyal-medya-fenomenleri-ile-dunyaya-tanitiyor 
edilerek gerçekleştirilmesi hem de Turizm ve Kültür Bakanlığı tarafından desteklenmesidir. Seçilen dijital diplomasi uygulaması, Turizm ve Kültür Bakanlığı'nın "Troya Ören Yeri"ni ve Türkiye'yi uluslararası kamuoyuna tanıtmak için oluşturduğu stratejinin bir parçasıdır.

Troya Ören Yeri'nin UNESCO Dünya Kültür Mirası Listesi'ne alınmasının yirminci yılı nedeniyle Turizm ve Kültür Bakanlığı çeşitli çalışmalar gerçekleştirmiştir. Bu çalışmalardan biri Troya'ya sosyal medya fenomenlerinin davet edilmesiyle, bölge ve Türkiye ile ilgili bilinirliğin artırılmasıdır. Etkinlik kapsamında farklı ülkelerden gelen yedi sosyal medya fenomeni ve içerik üreticisi Gelibolu Yarımadası, Çanakkale Şehitleri Anıtı, Truva Antik Kenti, Bozcaada, Alexandria Troas Antik Kenti ve Assos gibi turistik noktaları ziyaret etmiştir. Proje Güney Marmara Kalkınma ajansı ve bir seyahat platformu olan Gezimanya tarafından organize edilmiştir. ${ }^{3}$ Amaç, davet edilen sosyal medya fenomenlerinin paylaşımları aracılığıyla farklı ülke kamularının Çanakkale ve Türkiye hakkında bilgi sahibi olmalarının sağlanmasıdır.

Proje kapsamında da Sylvia Matzkowiak, Hoda Rostami, Dave Jones, Harjinder Kukreja, Vanessa Zilletti, John ve Jacinta Bender davet edilmiştir. ${ }^{4}$ Slyvia Matzkowiak, Polonya doğumlu, Alman vatandaşı olan bir sosyal medya fenomenidir. Almanca gezi yazılarını yayınladığı lifestyle-adventures.com isimli bir web sayfası ve 36.000 takipçisi bulunan "Goldie Berlin" isimli bir Instagram bloğu bulunmaktadırMatzjowiak kendisini "Influencer Pazarlama Müdürü" olarak tanımlamaktadır. ${ }^{5}$ Hoda Rostami, İran'ın en bilenen sosyal medya fenomenlerinden biridir, Instagram'da 446 bin takipçisi bulunmaktadır. Instagram'da kendisini gezgin ve "hikâye anlatıcısı" olarak tanımlamaktadır. ${ }^{6}$ Kendisini "profesyonel gezi bloggerı" olarak tanımlayan Amerikalı olan Dave Jones'un, jonesaroundtheworld isimli bir Web sayfası ve aynı isimde bir Instagram hesabı bulunmaktadır ${ }^{7}$. Instagram hesabında 65,2 bin takipçisi bulunmaktadır. Harjinder Kukreja, Hintli bir sosyal medya fenomenidir. Singh Lions isimli bir bloğu bulunmaktadır ve Instagram'da 220 bin takipçisi vardır. ${ }^{8}$ Kendini içerik üreticisi ve makyaj sanatçısı olarak tanımlayan Vanessa Zilletti, İtalyan bir sosyal medya fenomenidir ve Instagram hesabında 183 bin takipçisi bulunmaktadır ${ }^{9}$. Son olarak Josh ve Jacinta Bender "travel with bender" bloklarıyla ün kazanmıştır ancak daha önce Instagram hesaplarında yaklaşık 170.000 takipçi bulunan çift ${ }^{10}$, hesaplarını kapattıkları için araştırma dışında tutulmuştur.

3 Dünyanın Tanınmış Sosyal Medya Fenomenleri Çanakkale'de. Erişim 22 Aralık 2020, http://www. ezine.gov.tr/dunyanin-taninmis-sosyal-medya-fenomenleri-canakkalede

4 Dünyanın Tanınmış Sosyal Medya Fenomenleri Çanakkale'de. Erişim 22 Aralık 2020, http://www. ezine.gov.tr/dunyanin-taninmis-sosyal-medya-fenomenleri-canakkalede

5 Erişim 23 Aralık 2020, https://www.instagram.com/goldie_berlin/?hl=tr

6 Erişim 22 Aralık 2020, https://www.instagram.com/hodarostami/?hl=tr

7 Erişim 22 Aralık 2020, https://www.jonesaroundtheworld.com

8 Erişim 22 Aralık 2020, https://www.instagram.com/harjinderkukreja/?hl=tr

9 Erişim 22 Aralık 2020, https://www.instagram.com/vanessaziletti/?hl=tr

10 Erişim 22 Aralık 2020, https://travelwithbender.com/ 
Araştırmanın amacı, dijital diplomasi çalışmasında fenomenlerin gerçekleştirdikleri paylaşımları incelemek ve Türkiye'nin hangi özelliklerinin uluslararası kamuoyu ile paylaşıldığını ortaya çıkarmaktır. Bu bağlamda şu soruların yanıtları aranmıştır:

- Sosyal medya fenomenleri kaç paylaşım gerçekleştirmiştir?

- Paylaşımların içeriği (metin, fotoğraf, etiket) nasıldır?

- Paylaşımlarda Türkiye'nin hangi özellikleriyle ilgili bilgiler yer almaktadır?

- Türkiye'nin tarihi ile ilgili hangi bilgiler verilmiştir?

- Türkiye'nin turistik özellikleriyle ilgili hangi bilgiler verilmiştir?

- Türkiye'nin kültürel özellikleriyle ilgili hangi bilgiler verilmiştir?

- Paylaşımların interaktiflik düzeyi nedir? En çok beğeni ve yorum alan paylaşımlar hangileridir?

- En çok etkileşim alan paylaşımların diğer paylaşımlardan farkı nedir?

Soruların araştııılması için betimsel vaka analizi araştırma tekniği olarak kullanılmıştır. Vaka analizi ya da diğer adıyla örnek olay çalışması, bir olayın ya da sorunun detaylı olarak incelenmesinde niteliksel araştırma yöntemleri arasında en çok tercih edilen tekniklerden biridir. Bu teknik hem tekli hem çoklu biçimde kullanılabilmektedir. Başka şekilde ifade edilirse, bir vaka birey, grup, kurum, olay ya da büyük bir topluluk olabilir. Bu nedenle seçilen vaka analizi türü hem tek hem de birden fazla farklı olayı ortak kategoriler altında incelemeye olanak sağlamaktadır. Niteliksel bir araştırma tekniği olarak vaka analizinde "kapsamlı anlatım" ve "süreç-izleme" en önemli odak noktalarıdır (Given, 2008, s.22-68; Gilham, 2000). Buna istinaden vaka analizi bir olay ya da konunu yapısal ve dinamik özelliklerinin anlaşılmasını amaçlayan bir araştırma stratejisidir (Eisenhardt, 1989, s.534).

Vaka analizi sadece bir veri toplama aracı değildir, aynı zamanda çeşitli veri-inceleme analizlerini de içermektedir. Bu anlamda çeşitli vaka analizi tasarımları vardır. Araştırmacının amacı ve seçilen araştırma konusunun niteliğine göre değişiklik gösterebilmektedir. Ancak genel anlamda üç ana kategori altında toplanmaktadır: keşifçi, açıklayıcı ve betimsel. Diğerlerinden farklı olarak betimsel vaka analizinde herhangi konu/sorun/olay(lar) belirli bir kuramsal çerçevede ve sistematik olarak daha kapsamlı incelenebilmektedir (Berg, 2001, s.225-230). Sistematik bir betimsel vaka analizi için Yin (1994, s.21) beş temel özelliğin altını çizmektedir:
a- Araştırma sorusu
b- Kuramsal çerçeve
c- Araştırma nesnesinin belirlenmesi
d- Mantıksal çerçeve
e- Bulguları yorumlama 
Sosyal medya fenomenlerinin, proje süresince gerçekleştirdiği paylaşımlar üç ana kategori altında incelenmiştir. İlk kategori paylaşımların içeriğidir. Bu kategoride Instagram paylaşımlarında kullanılan fotoğraflar, fotoğrafların altında yer alan metin ve etiket'ler incelenmiştir. İkinci kategori, paylaşımlarda Türkiye'nin temsilidir. Bu kategoride Türkiye ile ilgili hangi bilgilerin paylaşıdığı araştırılmıştır. Son kategori etkileşimli ortamdır. Dijital diplomasinin ayırt edici özelliği etkileşim ve karşılılık ilişkinin kurulmasına olanak sağlamasıdır. Bu bağlamda paylaşımların etkileşim düzeyi ve en çok etkileşim alan paylaşımlar incelenmiştir.

\section{Bulgular}

Betimsel örnek olay çalışması ile yapılan araştırmada bulguların daha detaylı incelenmesi için üç ana başlık belirlenmiştir. Her bir başlık kamu diplomasisinin temel özelliklerine uygun şekilde hazırlanmıştır. Araştırma kapsamında Alman, İranlı, Amerikalı, Hintli ve İtalyan beş Instagram fenomeninin hesapları incelenmiştir. Proje kapsamında Çanakkale'de ağırlanan ve tarihi, kültürel bölgeleri gezen sosyal medya fenomenleri 1 Ekim ile 5 Ekim 2018 tarihleri arasında çeşitli paylaşımlar gerçekleştirmiştir. Bu paylaşımlar bir yandan bölgeyi turistik olarak tanımlarken, diğer yandan Türkiye ve Türkiye tarihi ile ilgili ve Türkiye'nin nasıl bir ülke olduğu ile ilgili fikir vermektedir. Dolayısıyla fenomenlerin paylaşımları hem kültürel hem de turistik özellikleriyle temel olarak Instagram üzerinden gerçekleştirildiği için, bir yumuşak güç unsuru olarak kabul edilen "dijital diplomasi" çerçevesinde ele alınmıştır.

\section{Paylaşımların İçeriği}

Paylaşımların içeriği üç kriter doğrultusunda incelenmiştir: fotoğraf, metin ve etiket. Kullanılan fotoğraflar Türkiye'nin nasıl gösterildiği, metin ise nasıl tanımlandığını göstermesi açısından önemlidir.

Tablo 1. Instagram Paylaşım ve Fotoğraf Sayısı

\begin{tabular}{|l|l|l|}
\hline & Paylaşım Sayısı & Fotoğraf Sayısı \\
\hline Harjinder Kukreja & 7 & 11 \\
\hline Hoda Rostami & 3 & 4 \\
\hline Dave Jones & 3 & 3 \\
\hline Goldie Berlin & 5 & 5 \\
\hline Vanessa Zilletti & 4 & 4 \\
\hline Toplam & $\mathbf{2 2}$ & $\mathbf{2 7}$ \\
\hline
\end{tabular}

Farklı ülkelerden gelen beş sosyal medya fenomeni, Instagram hesapları aracılığıyla toplam 27 fotoğraf paylaşmıştır. En çok fotoğraf (11), Hindistan'dan gelen Harjinder Kukreja tarafından paylaşılmıştır. En az fotoğraf ise Dave Jones tarafından paylaşımıştır. Fotoğraflara ek olarak, Harjinder Kukre- 
ja, bir video da paylaşmıştır. Video öncelikle çay bardağını göstermekte, daha sonra Kukreja çay içerken görülmektedir. ${ }^{11}$

Tablo 2. Fotoğraf İçerikleri

\begin{tabular}{|l|l|}
\hline Fotoğraf İceriği & Sayı \\
\hline İstanbul (manzara) & 2 \\
\hline Gelibolu (anıt) & 2 \\
\hline Zeus Altarı & 1 \\
\hline Gelibolu (Anzak Anıtı) & 3 \\
\hline Troya Atı & 2 \\
\hline Bozcaada Polante Feneri & 2 \\
\hline Bozcaada (sokaklar, kafeler) & 6 \\
\hline Asos Athena Tapınağı & 2 \\
\hline Çay & 1 \\
\hline Çanakkale Manzara (Wind-Rose Sunset Point) & 3 \\
\hline Feribot & 1 \\
\hline Asos Antik Tiyatro & 1 \\
\hline Türkiye dışı & 1 \\
\hline Toplam & $\mathbf{2 7}$ \\
\hline
\end{tabular}

Tablo 2' de paylaşılan fotoğrafların içerikleri verilmektedir. Bu bağlamda en çok Bozcaada'nın renkli sokakları, kafeleri ve kapılarının fotoğraflarının paylaşıldığı görülmektedir. Bu kategoriyi, Çanakkale manzara fotoğrafları ve Gelibolu Anzak anıtının fotoğrafı takip etmektedir. Fotoğrafların yalnızca üçünde Türkiye'de yaşayan insanlar resmedilmiştir. Bir tanesi Feribot'ta çekilmiştir ve yolculuk eden bir kişi fotoğraflanmıştır, diğeri Bozcaada sokaklarında köpeğini gezdiren yaşı bir adamdır ve sonuncusu Troya Anıtı önünde Harjinder Kukreja ve kazı çalışmalarında önemli bir isim olan Arkeolog Prof. Dr. Rüstem Aslan'ın fotoğrafıdır ${ }^{12}$. Fotoğrafların ağırlıklı olarak manzara resimlerinden oluştuğu görülmektedir. Hoda Rostami'nin paylaştığı fotoğraflardan biri'13 ise, Türkiye ile ilgili değildir.

Tablo 3. Metin İçerikleri

\begin{tabular}{|l|l|}
\hline Bozcaada ile ilgili bilgi & 7 \\
\hline Tarihi bilgi & 5 \\
\hline İstanbul'un güzelliği & 1 \\
\hline Türk çayı & 2 \\
\hline Atatürk & 1 \\
\hline Sihlerle ilgili metin & 1 \\
\hline Günbatımının güzelliği & 3 \\
\hline Diğer & 1 \\
\hline
\end{tabular}

11 Erişim 22 Aralık 2020, https://www.instagram.com/p/BoXCSOSIwk7/

12 Erişim 23 Aralık 2020, https://www.instagram.com/p/BogfYuqFSal/

13 Erişim 23 Aralık 2020, https://www.instagram.com/p/BojBmO9I8YX/ 
Paylaşımların altında bulunan içerikler kategoriler altında incelendiğinde, yedi paylaşımın Bozcaada ile ilgili olduğu görülmektedir. Paylaşımlarda Bozcaada'ya nasıl gidileceği, nasıl vakit geçirileceği ve bölgenin güzelliği ile ilgili bilgiler bulunmaktadır. İinci olarak tarihsel olaylarla ilgili bilgi paylaşımı yapıldığı görülmektedir. Beş paylaşımda Truva Savaşı, Athena Tapınağı, Gelibolu Savaşı ile ilgili tarihsel bilgiler bulunmaktadır. Üç paylaşımda Çanakkale'de günbatımından söz edilmiş, iki paylaşım çayın Türk kültüründeki yeri ile ilgili bilgi verilmiştir. Atatürk, İstanbul ve Sihler ile ilgili birer paylaşım bulunurken, Türkiye ve bölgeyle ilgili herhangi bir bilgi içermeyen bir metin bulunmaktadır.

Tablo 4. Etiketler

\begin{tabular}{|l|l|}
\hline \#Canakkale & 20 \\
\hline \#Homeoftroy & 15 \\
\hline \#Turkey & 8 \\
\hline \#Gallipoli & 1 \\
\hline \#Sikh & 1 \\
\hline \#Turkiye & 1 \\
\hline \#Polente & 1 \\
\hline \#Bozcaada & 1 \\
\hline \#Troy & 1 \\
\hline \#Trojanhorse & 1 \\
\hline \#Trojanwar & 1 \\
\hline \#Greeks & 1 \\
\hline \#AltarofZeus & 1 \\
\hline \#Ataturk & 1 \\
\hline \#Istanbul & 1 \\
\hline \#Withgalaxyturkey & 1 \\
\hline \#Troy2018 & 1 \\
\hline \#Vanessaonthego & 1 \\
\hline \#Visitturkey & 2 \\
\hline \#Beautiful destionations & 1 \\
\hline \#Adv & 1 \\
\hline
\end{tabular}

Instagram'da etiket kullanımı içeriklerin daha fazla kişiye ulaşmasını, paylaşımların daha çok beğeni ve yorum almasını sağlamaktadır. Bir konunun Instagram'da duyulması için bir etiket stratejisi oluşturulması gerekmektedir. Paylaşımlarda bir etiket stratejisi olmadığı zaman, hedef kitleye ulaşmak zorlaşmaktadır. Dijital diplomasi çalışması incelendiğinde bir etiket stratejisi olmadığı görülmektedir. En çok kullanılan etiketler \#Canakkale, \#homeoftroy ve \#turkey'dir. Ancak bu etiketler bütün paylaşımlarda kullanılmamıştır. \#visitturkey iki, diğer etiket'ler ise yalnızca birer kez kullanılmıştır. Bu durum paylaşımların daha fazla kişiye ulaşmasını engellemektedir. 


\section{Paylaşımlarda Türkiye'nin Temsili}

Kamu diplomasisinin amacı, uluslararası kamuoyunda ülke ile ilgili olumlu bir imaj oluşturmak, ülke ile ilgili bilgilenmelerini sağlamaktır. Bu bağlamda Instagram paylaşımlarının Türkiye'nin hangi özelliklerini tanıttıklarının incelenmiştir. Paylaşımlar incelendiğinde Türkiye'nin temsilinin üç tema etrafında şekillendiği görülmektedir: Tarih, turistik özellikler ve kültürel özellikler.

Tarih teması altında, paylaşımlarda Türk topraklarında yaşanan savaşlar ve bulunan anıtlar ile ilgili tarihi bilgiler paylaşılmıştır. Goldie Berlin, Asos'ta bulunan Athena tapınağının, M.Ö. 530 yılında inşa edildiğini ve Anadolu'daki Dor düzeni (doric style) ile yapılan tek tapınak olduğunu paylaşmıştır. ${ }^{14}$ Asos'taki Amfi Tiyatro'nun resmi altında ise, Asos'un tarihiyle ilgili bilgi vermiştir. Asos'un aynı zamanda Behremkale ya da Behram olarak bilindiği, Çanakkale'nin Ayvacık bölgesinde küçük ama tarihi olarak zengin bir kasaba olduğunu ifade etmiştir. ${ }^{15}$ Dave Jones, Bozcaada'nın Yunan adalarını anımsattığını ancak Bozcaada'da daha önce Yunanlılar ve Türklerin birlikte yaşadığını öğrendiği için bunun doğal olduğunu yazmıştır. ${ }^{16}$ Harjinder Kukreja, Truva Savaşı'nın hikâyesini paylaşmıştır. Truva Antik şehrinde bulunmanın çok güzel olduğunu belirten Kukreja, Yunanlıların Truva şehrine girip savaşı kazanmak için kullandıkları hilenin hikâyesinin çok ilginç olduğunu söylemiştir. 10 yıllık sonuçsuz bir kuşatmadan sonra Yunanlıların büyük tahta bir at yaptığı ve seçkin askeri içine sakladığı bilgisini paylaşmışır. Bunun yanı sıra Kukreja, Çanakkale Savaşı ile ilgili duygularını paylaşmış ve Gelibolu'da bulunan Anzak Anıtı'nın önünde paylaştığı fotoğrafa, 1. Dünya Savaşı askerlerine saygılarını ilettiğini yazmış. Ve "Modern Türkiye'nin kurucusu Atatürk"ün, Gelibolu'da hayatını kaybeden askerleri onurlandırdığı yazısını paylaşmıştır. ${ }^{17}$

“Kanlarını döken ve yaşamlarını yitiren kahramanlar... Şimdi dost bir ülkenin topraklarında yatıyorsunuz. Huzur içinde uyuyunuz. Bizim ülkemizin topraklarında yan yana yatan Coniler ile Mehmetlerin arasında bize göre bir fark yoktur. Siz, oğullarını uzak ülkelere gözyaşları içinde gönderen anneler... Sizin oğullarınız şimdi huzur içinde bizim bağrımızda yatıyorlar. Onlar da bu topraklarda yaşamlarını yitirdikten sonra, bizim çocuklarımız olmuşlardır" Atatürk, 1934.

Turistik özellikler temasının altında bölgenin turistik özellikleriyle ilgili bilgiler yer almaktadır. Çanakkale'nın "çok güzel ve resim gibi"18 (Goldie Berlin) bir yer olduğu belirtilmiş, "tarihi, anıları ve tarihi binaları" (Goldie Berlin) ${ }^{19}$ bulunduğu ve manzaranın ne kadar güzel olduğu (Harjinder Kekreja ${ }^{20}$, Goldie Berlin ${ }^{21}$, Dave

14 Erişim 23 Aralık 2020, https://www.instagram.com/p/BoeF4kCH3GQ/

15 Erişim 23 Aralık 2020, https://www.instagram.com/p/BodUO1unHvy/

16 Erişim 23 Aralık 2020, https://www.instagram.com/p/BokB3dPBJve/

17 Erişim 23 Aralık 2020, https://www.instagram.com/p/BoZTxBKICzX/

18 Erişim 24 Aralık 2020, https://www.instagram.com/p/Boitsdynq89/

19 Erişim 24 Aralık 2020, https://www.instagram.com/p/Boitsdynq89/

20 Erişim 24 Aralık 2020, https://www.instagram.com/p/BojMSmUFkP7/

21 Erişim 24 Aralık 2020, https://www.instagram.com/p/BoZTxBKICzX/ 
Jones $^{22}$ ) vurgulanmıştır. Bunun yanı sıra Çanakkale ve civarında neler olduğu anlatımıştır: Butik oteller, B\&B'ler, barlar, rengârenk boyanmış evlerle dolu Yunan mahallesi (Goldie Berlin) ${ }^{23}$ şarap tadımı, günbatımı (Dave Jones ${ }^{24}$ ). Bölgenin görülmesi gereken bir yer olduğunu ifade eden Goldie Berlin ${ }^{25}$ ve Dave Jones ${ }^{26}$, Bozcaada'ya nasıl gidileceğini tarif etmiştir, Eceabat'tan 30 dakikalık bir yolculukla bölgeye ulaşılabileceği bilgisi paylaşılmıştır.

Dave Jones, Türkiye'yi "yatırım yapılabilecek bir ülke" olarak tanımlamış, "buraya yazın gelmeye can atıyorum" ifadesiyle görülmesi gereken bir yer olduğunu vurgulamıştır. ${ }^{27}$ Bunun yanı sıra Çanakkale'yi "etkileyici", "güzel" ve "inanılmaz" ifadeleriyle tanımlamıştır. Kukreja'nın İstanbul'da Sultanahmet Cami önünde paylaştığı fotoğrafın altında Alphonse de Lamartine'nın "Dünyaya bir kez bakmak zorundaysan, İstanbul'a bak" sözü yer almaktadır.

Kültürel özelikler temasının altında Türkiye'nin yeme-içme kültürü ve misafirperverliğinden de söz edilmiştir. Ancak bu bilgileri içeren paylaşımların sayısı diğerlerine kıyasla oldukça azdır. Hoda Rostami, Bozcaada'da bir kahvaltı masasının fotoğrafının altında hem Bozcaada'yı betimlemiş hem de Türk kültürü ile ilgili bilgi vermiştir. Rostami paylaşımda masada bulunanları ve konuşulanları hikâyeleştirerek anlatmıştır. Bulundukları yeri edebi bir dille "sakin bir suyun yanında", "rüzgârda sallanan botlar" gibi ifadelerle tanımlamıştır. Masanın üzerinde bulunan "el işlemli mendiller", "el yapımı seramik fincanlarda" servis edilen Türk kahvesinden, kadınların elleriyle yaptığı "peynir, tereyağı, reçeller ve ekmek" ten söz etmiştir. Aynı paylaşımının sonunda "komşu ülkenin bölge turizmini tanıtmak için gerçekleştirdiği bu etkinlik ve blog yazarlarını davetinin" ona ilginç geldiğini ve bu nedenle proje sorumlusuna bunun ne kadar etkili olacağını düşündüklerini yazmıştır. Ve proje sorumlusunun yanıtını paylaşmıştır: "Kahvenizi yudumlayın ve düşünün. Her bin kişiden biri Çanakkale adını hatıllasa, bugün ve gelecek için işimizi yaptık demektir." ${ }^{28}$

Kukreja, Türklerin çayı tadı için içtiklerini ama aynı zamanda misafirliğin bir simgesi olarak sunduklarını ifade ederken, Zilletti, misafirperverliği simgelediğini söylediği çayın günün herhangi bir saatinde kendine özgü bir bardakla servis edildiği bilgisini paylaşmıştır. Aynı zamanda çaya âşık olduğunu yazmıştır. ${ }^{29}$

\section{Etkileşimli Ortam}

Etkileşimli ortama olanak sağlaması, dijital diplomasinin önemli özelliklerinden biridir. Instagram bağlamında düşünüldüğünde etkileşimi gösteren iki faktör bulunmaktadır: Beğeni sayısı ve yorum. Aynı zamanda paylaşımlara gelen

22 Erişim 24 Aralık 2020, https://www.instagram.com/p/BohC4YBBm8Y/

23 Erişim 24 Aralık 2020, https://www.instagram.com/p/Boitsdynq89/

24 Erişim 24 Aralık 2020, https://www.instagram.com/p/BofQfGzBWdJ/

25 Erişim 24 Aralık 2020, https://www.instagram.com/p/Bof692AnaPe/

26 Erișim 24 Aralık 2020, https://www.instagram.com/p/BokB3dPBJve/

27 Erişim 24 Aralık 2020, https://www.instagram.com/p/BokB3dPBJve/

28 Erişim 24 Aralık 2020, https://www.instagram.com/p/Bof9YtxF2Mj/

29 Erişim 24 Aralık 2020, https://www.instagram.com/p/BoeGpUhgQ7Z/ 
yorumların, sosyal medya fenomenleri tarafından cevaplanıp, cevaplanmadığı da etkileşimi gösteren önemli değişkenlerden biridir. Sosyal medya fenomenlerinin paylaşımları toplan 163.106 beğeni ve 2.321 yorum almıştır. Tablo 5 'te görüldüğü üzere en çok beğeni ve yorum alan paylaşımlar büyük bir farkla Hoda Rostami'nin paylaşımlarıdır. En az beğeni ve yorum alan paylaşımlar ise Dave Jones'a aittir.

Tablo 5. Beğeni ve Yorum Sayısı

\begin{tabular}{|l|l|l|l|}
\hline & Paylaşım Sayısı & Toplam Beğeni Sayısı & Toplam Yorum Sayısı \\
\hline Harjinder Kukreja & $6^{30}$ & 15.575 & 256 \\
\hline Hoda Rostami & 3 & 87.593 & 1.249 \\
\hline Dave Jones & 3 & 10.017 & 155 \\
\hline Goldie Berlin & 5 & 22.175 & 469 \\
\hline Vanessa Zilletti & 4 & 27.746 & 192 \\
\hline Toplam & $\mathbf{2 2}$ & $\mathbf{1 6 3 . 1 0 6}$ & $\mathbf{2 . 3 2 1}$ \\
\hline
\end{tabular}

Bu bölümde sosyal medya fenomenlerinin en çok beğeni ve yorum alan paylaşımları incelenmiştir. Goldie Berlin hesabının gerçekleştirdiği paylaşımlarda en çok beğeni (5.352 beğeni) alan paylaşım, Rüzgârgülü Günbatımı noktasında paylaştığı fotoğraftır. ${ }^{31}$ Fotoğrafın altında Çanakkale'nin tarihi ve güzel bir bölge olduğu yazılmıştır.

Ancak en çok yorum (114 yorum) alan paylaşım, Hoda Rostami'nin Bozacada'daki bir kapı önünde çekilmiş fotoğrafını gerçekleştirdiği paylaşımdır. Bu fotoğrafın altına gelen yorumların hemen hemen hepsi fotoğrafın ve fotoğraf çekilen bölgenin ne kadar güzel olduğu ile ilgilidir. Goldie Berlin bu yorumların, 19'una teşekkür ederek cevap vermiştir. Türkçe yazılan bir "günaydın canım" yorumuna ise Türkçe "günaydın canım" şeklinde yanıt vermiştir. ${ }^{31}$

Dave Jones'un en çok beğeni alan (4.357 beğeni) ve en çok yorum alan (91 yorum) paylaşımı aynıdır. Bu fotoğraf, Goldie Berlin hesabının paylaştığı fotoğrafla aynı noktada çekilmiştir. Fotoğrafın alıında manzaranın ne kadar harika olduğundan bahsedilmektedir. Gelen yorumlar genellikle fotoğrafın ne kadar güzel olduğu ve kristal topun nereden alındığı ile ilgilidir bu yorumların 35'ine yanıt verilmiştir. Gelen yorumlardan biri "bölgenin gerçek dışı" göründügünü ve buraya geleceğini içermektedir. Dave Jones yanıt olarak, Türkiye'nin harika bir ülke olduğunu söylemiştir. ${ }^{32}$

Harjinder Kukreja'nın en çok beğeni (3.280 beğeni) ve yorum (60 yorum) alan paylaşımı aynıdır. Paylaşımda Kukreja, Anzak Anıtının önünde poz vermiş ve açıklamada kendisiyle ilgili çıkan haberin linkini paylaşmıştır. Haberde Çanakkale Savaşı'nda hayatını kaybeden Sihlere saygılarını sunduğu ifadesi bulunmaktadır. Bu paylaşımda Çanakkale ya da Türkiye ile ilgili bir bilgi bulunmamaktadır. Paylaşı-

30 Paylaşım sayısı olarak 7 yerine 6 verilmiştir. Çünkü Instagram'da video paylaşımı yapııdığı zaman, beğeni değil "görüntülenme sayısı" bilgisi paylaşılmaktadır.

31 Erişim 24 Aralık 2020, https://www.instagram.com/p/Boitsdynq89/

32 Erişim 24 Aralık 2020, https://www.instagram.com/p/BofQfGzBWdJ/ 
mın altına gelen yorumların hepsi, Kukreja'yı tebrik etmektedir. Kukreja, yalnızca birine "kalp" emojisi göndererek yanıt vermiştir. ${ }^{33}$

Vanessa Ziletti'nin paylaşımlarında en çok beğeni (10.076) ve en çok yorum (67 yorum) paylaşım Ziletti'nin gün batımında Asos'ta paylaştığı fotoğraftır. Bu paylaşım, diğer sosyal medya fenomenlerinin arasında da en çok etkileşim alan paylaşımdır. Paylaşımda yalnızca "Muhteşem Günbatımı" ifadesi yer almaktadır. Yorumların çoğu beğeni ifadesi içermektedir ve Ziletti yalnızca bir yoruma "teşekkür ederim" şeklinde cevap vermiştir. Ziletti'nin yalnızca bir yoruma yanıt vermesi, etkileşimin düşük olduğunu göstermektedir. ${ }^{34}$

Son olarak Hoda Rostami'nin en çok beğeni (36.000) ve en çok yorum (631) alan paylaşımı, Bozcaada'da bir kapının önünde çekilen fotoğraftır. Bu fotoğrafın altında Rostami, nasıl başarııı bir blogger haline geldiğini, yaşadığı zorlukları, geçirdiği hastalıkları anlatmıştır. Bu fotoğrafın altında Çanakkale ya da Türkiye ile ilgili bir ifade bulunmamaktadır. Yorumların çoğu empati ve takdir ifadeleri içermektedir.

En çok etkileşim alan fotoğraflar incelendiğinde beş fotoğrafın üçünün günbatımı fotoğrafı olduğu görülmektedir. Diğerleri ise Hoda Rostami'nin renkli kapı önündeki ve Harjinder Kukreja'nın Anıt önündeki fotoğraflarıdır. Etkileşimi düşük olan fotoğraflarda ise ağırlıklı olarak tarihi mekânların paylaşıldığı görülmektedir. Sosyal medya fenomenlerinin kendilerinin görünmediği fotoğraflar daha az etkileşim almıştır. Hem sosyal medya fenomenlerinin bulunduğu hem de "güzel bir manzara" içeren fotoğraflar diğerlerinden daha fazla etkileşim almıştır. Harjinder Kukreja'nın Anıt önündeki fotoğrafının en çok etkileşim alan paylaşım olmasının ise altına yazılan mesaj olduğu düşünülmektedir. Kukreja bu fotoğrafın altında Sihler ve Çanakkale savaşı ile ilgili duygusal bir metin paylaşmıştır.

\section{Sonuç}

Yapılan çalışmada Instagram bir kamu diplomasisi aracı olarak ele alınmış ve sosyal medya fenomenlerinin kullanıldığı bir dijital diplomasi çalışması örnek olay olarak seçilmiştir. Örneklem çerçevesinde 2018 yılında Troya yılı kapsamında Troya Ören Yeri'nin UNESCO Dünya Kültür Mirası Listesi'ne alınmasının yirminci yılı nedeniyle Turizm ve Kültür Bakanlığı tarafından Instagram üzerinden yedi sosyal medya fenomeni katıımıyla gerçekleştirilen etkinlik ele alınmıştır. İki fenomenin hesabını kapatması nedeniyle sadece beşinin paylaşımlarına erişilmiştir.

Çalışma kapsamında geleneksel diplomasi anlayışının artık tek yönlü işlevinin yetersiz kaldığı ve kitlelerin, kamuların daha interaktif ve yinelemeli bir iletişime intiyaç duydukları (Collins, DeWitt ve LeFebvre, 2019), bu doğrultuda başta sosyal ağ siteleri olmak üzere dijital platformların önemli bir "yumuşak güç" bileşenlerine dönüştükleri görülmüştür. Bu anlamda "dijital diplomasi", dış politi-

33 Erişim 24 Aralık 2020, https://www.instagram.com/p/BogNseiF_OK/

34 Erişim 24 Aralık 2020, https://www.instagram.com/p/Boem3b6gpkf/ 
kanın dijital medya üzerinden yürütülmesini içeren bir kavram olarak ele alınmıştır (Özlü ve Alan, 2020). Dijitalleşme sürecinin hızla geliştiği günümüz dünyasında dijital diplomasi, kamu diplomasisi için yeni olanaklar ve araçlar sunmuştur. Özellikle hükümetlerin küresel medya ekolojisi içerisinde tek yönlü iletişim biçimleri yerine, iki yönlü- simetrik iletişim kurma fırsatı sunduğu görülmektedir (Kampf, Manor ve Segev, 2015, s.337). Sosyal medya araçları ülkeler arasında bağlantılar kurmakta ve kamu diplomasisi faaliyetlerinde bu bağlantıların farklı halkla ilişkiler stratejilerine yönelik olarak etkin kullanılmaktadır (Boyle, 2019, s.122).

Çalışmada Instagram'ın dijital diplomasi bağlamında daha da etkili kullanılabilmesi için öneriler araştırma bulgularına göre belirlenmiştir. Bu anlamda öncelikle Instagram'ın görsel ve sözel özellikleriyle dijital diplomasi için etkili ve etkileşimli bir platform sunduğu vurgulanabilir. Ancak çok daha büyük potansiyel olmasına karşın, dijital diplomasi açısından bakıldığında Türkiye'nin "yumuşak güç" araçlarından biri olması için daha başarılı ve kapsamlı stratejilerin hazırlanması ve uygulanması gerekmektedir. Sosyal medya fenomenleri tarafından gerçekleştirilen paylaşımlar incelendiğinde, paylaşımların ağırlıkı olarak kültürel ve turistik bilgiler içerdiği görülmüştür. Türkiye'nin kültürel özellikleriyle ilgili yalnızca "misafirperverlik" öne çıkarılmıştır. Misafirperverlikten yalnızca iki sosyal medya fenomeni söz etmiştir. Etiketler incelendiğinde de bir tutarlıık olmadığı görülmektedir. Örneğin Türkiye'nin etiketlenmesi için bazen \#turkey, bazen \#turkiye bazense \#visitturkey kullanılmıştır. Ziyaret edilen kültürel mekânlar için de benzer şekilde farklı etiket'ler kullanıldığı görülmektedir. Bu durum Türkiye kurumları tarafından gerçekleştirilen bir dijital diplomasi etkinliğindeki strateji eksikliğini göstermektedir.

Bunun yanı sıra, sosyal medya araçlarının diplomasi için sunduğu en önemli fırsat etkileşimli bir ortam yaratmasıdır. Etkileşim beğeni ve yorum sayıları üzerinden değerlendirilmiştir. Gerçekleştirilen paylaşımlara gelen yorum sayısının fazla olmadığı görülmektedir. Sosyal medya fenomenlerinin paylaşımlarının altında Türkiye özelinde bir diyalog oluşmamıştır. Aynı zamanda fenomenlerin yapılan yorumlara genellikle yanıt vermedikleri, verdikleri yanıtların ise diyaloğu sürdürmeye yönelik olmadığı görülmektedir. Dolayısıyla bu çalışma kapsamında, Instagram'ın etkileşim özelliğinden çok da yararlanılamadığı düşünülmektedir. Sosyal medya araçları üzerinden yapılan etkinliklerin çok daha fazla sistemli ve kontrollü yapılması dijital diplomasi bağlamında amaçlara ulaşmada önemlidir.

Çalışmanın sınırları çerçevesinde spesifik bir örneklemin incelenmesi ile elde edilen bulguların genelleştirilmesi mümkün olmasa da ileride yapılacak çaIışmalara kuramsal ve uygulama olarak katkı sağlayacağı düşünülmektedir. Gelecekte daha kapsamlı çalışmalarla farklı ülke bağlamlarının karşılaştııımasıyla daha farklı sonuçlar ve öneriler ortaya çıkabilir. Instagram'ın daha farklı özelliklerinin kullanılabilirliğine yönelik stratejiler geliştirilebilir. 


\section{Kaynakça}

Adesina, S. O. (2017). Foreign policy in an Era of Digital Diplomacy. Cogent Social Sciences, 3 (1), 1-13.

Boyle, J. (2019). Twitter Diplomacy Between India and The United States: Agenda-BUilding Analysis of Tweets during Presidential Visits. Global Media and Communication, 15 (1), 121-134.

Bull, H. (1997). The Anarchical Society: A Study of Order in World Politics. Houndmills: Macmillan

Collins, D. S., DeWitt, R, J. ve Le Febvre, K, R. (2019). Etiket Diplomacy: Twitter as a Tool for Engaging in Public Diplomacy and Promoting US.Foreign Policy, 15, 78-96.

Çavuş, T. (2012). Dış Politikada Yumuşak Güç Kavramı ve Türkiye'nin Yumuşak Güç Kullanımı. Kahramanmaraş Sütçü İmam Üniversitesi İktisadi ve İdari Bilimler Dergisi, 2 (2), 23-36.

Çömlekçi, F. M. (2019). Dijitalleşen Diplomasi ve Sosyal Medya Kullanımı: Büyükelçilik Facebook Hesapları Üzerine bir Araştırma. Kırklareli Üniversitesi İktisadi ve İdari Bilimler Fakültesi Dergisi, 8 (1), 1-13.

Eisenhardt, K.M. (1989). Building Theories from Case Study Research.The Academy of Management Review 14 (4), 532-550

Gilhem, B. (2000). Case Study Reseah Methods. New York: Continuum.

Given, M. L. (2008). The Sage Encyclopedia of Qualitative Research Methods. Thousand Oaks: Sage.

Grix, J. ve Brannagan, M. P. (2016) Of Mechanisms and Myths: Conceptualising States' "Soft Power" Strategies through Sports Mega-Events. Diplomacy \& Statecraft, 27 (2), 251-272.

Hanson, F. (2012). Baked in and Wired: eDiplomacy@State. Foreign Policy Paper Series no 30, 1-41.

Harris, B. (2013). Diplomacy 2.0: The Future of Social Media in Nation Branding. Exhange: The Journal of Public Diplomacy. 4, 17-31.

Heng, Y-K. (2010). Mirror, Mirror on the Wall, Who is The Softest of Them All? Evaluating Japanese And Chinese Strategies in The 'Soft' Power Competition Era. International Relations of the Asia-Pacific, 10, 275-304.

Huijgh E. (2016). Public diplomacy. Constantinou CM, Kerr P ve Sharp P (Ed.), The SAGE Handbook of Diplomacy(437-450). London: Sage.

Ittefaq, M. (2019). Digital Diplomacy via Social Networks: A Cross-National Analysis of Governmental Usage of Facebook and Twitter for Digital Engagement. Journal of Contemporary Eastern Asia, 18 (1), 49-69. 
Kampf, R., Manor, I. Ve Segev, E. (2015). Digital Diplomacy 2.0? A Cross-National Comparison of Public Engagement in Facebook and Twitter. The Hague Journal of Diplomacy, 10, 331-362.

Korkmaz, A. ve Böyük, M. (2019). Sosyal Medya Ortamlarının Diplomasi İletişiminde Kullanımı: Weibo Sosyal Medya Platformu Örneği. Simetrik İletişim Araştırmaları Dergisi, 1 (1), 37-47.

Köse, E. (2017). Dijital Diplomasinin Sosyo-Ekonomik ve Sosyo-Politik Yapıya Etkisi. Süleyman Demirel Üniversitesi İktisadi ve İdari Bilimler Dergisi, 22 (15), 2347-2370.

Manor, I. Ve Crilley, R. (2020). The Mediatisation of MFAs: Diplomacy in the New Media Ecology. The Hague Journal of Diplomacy, 15, 66-92.

Melissen, J. (2013). Public diplomacy. A. Cooper, J. Heine, R. ve Thakur (Ed.), The oxford Handbook of Modern Diplomacy (436-452). Oxford: Oxford University Press.

Melissen, J ve de Keulenaar, E. V. (2017). Critical Digital Diplomacy as a Global Challenge: The South Korean Experience.Global Policy, 8 (3), 294-302.

Nye, S. J. (2004). Soft Power and American Foreign Policy. Political Sicence Quarterly, 119 (2), 255-270

Nye, S. J. (2009). Get Smart: Combining Hard and Soft Power. Foreign Affairs, 88 (4), 160-163.

Özlü, Ö. Ve Alan, A. G. (2020). Kamu Diplomasisi Oluşturulmasında Dijital DipIomasinin Etkisi: Türkiye'de Bulunan Büyükelçiliklerin Twitter Kullanımı. Erciyes İletişim Dergisi, 7(2), 1345-1366).

Rashica, V. (2018). The Benefits and Risks of Digital Diplomacy. SEEU Review, 13 (1), 75-89.

Sancar, A. G. (2016). Yumuşak Güç Kaynağı olarak Kültür ve Türkiye'nin Yumuşak Gücünde Kültür Faktörü. Balkan ve Yakın Doğu Sosyal Bilimler Dergisi, 2 (4), 1626.

Sancar, A. G. (2017a). Turizm Diplomasisi Kapsamında Yer Markalama: Turkey Home Kampanya Analizi. Selçuk Iletişim, 9 (4), 89-108.

Sancar, A. G. (2017b). Dijital Diplomaside Instagram'ın Rolü: Come See Turkey Örneği. Öztürk, G. ve Eken, I. (Ed.), 1st International Conference on New Trends in Communication (371-381). İstanbul: İstanbul Ticaret Üniversitesi.

Spy, D. (2018). Facebook Diplomacy: A Data-Driven, User-Focused Approach to Facebook use by Diplomati Missions. Media International Australia, 168 (1), 6280

Sergunin, A. ve Karabeshkin, L. (2015). Understanding Russia's Soft Power. Politics, 35 (3-4), 347-363. 
Snow, N. (2009). Rethinking Public Diplomacy. Nancy Snow \& Philip M. Taylor (Ed.), Routledge Handbook of Public Diplomacy (1-9). New York: Routledge International Handbooks.

Straus, N., Kruikemeier, S., Van der Meulen, H., ve Van Noort, G. (2015). Digital Diplomacy in GCC Countries: Strategic Communication of Western Embassies on Twitter. Government Information Quarterly, 32, 369-379.

Tuncer, F. F. (2020). Uluslararası Illişkilerin Dijital Dönüşümü: Twitter Diplomasisi. i.E. Çelik (Ed.), Dijital Dönüşüm: Ekonomik ve Toplumsal Boyutlarıyla (195-209). Ankara: Gazi Kitabevi.

Watson, A. (1984). Diplomacy: The Dialogue Between States. New York: Routledge.

Yağmurlu, A. (2019). Dijital Diplomasi: Kamu Diplomasisi Çerçevesinden Avrupa Birliği Üye Ülkeleri ve Türkiye Dışişleri Bakanlık Internet Uygulamaları. Gümüşhane Üniversitesi İletişim Fakültesi Elektronik Dergisi, 7(2), 267-295.

Yapıcı, U. (2015). Yumuşak Güç Ölçülebilir mi? Uluslararası Ilişkiler/International Relations, 12 (47), 5-25.

Yin, K. R. (2003). Case Study Research: Design and Methods. Thousand Oaks: Sage.

We Are Social Raporu 2020. Erişim 22 Aralık 2020, https://wearesocial.com/digital-2020 